\title{
An oasis in the desert: The potential of water sources as camera trap sites in arid environments for surveying a carnivore guild.
}

\author{
Sarah Edwards ${ }^{* 1,2}$, Alan C. Gange ${ }^{2}$, Ingrid Wiesel ${ }^{1,3}$ \\ ${ }^{1}$ Brown Hyena Research Project, P.O. Box 739, Lüderitz, Namibia. \\ ${ }^{2}$ School of Biological Sciences, Royal Holloway, University of London, Egham Hill, Egham, Surrey, TW20 0EX, \\ UK. \\ ${ }^{3}$ Centre for Wildlife Management, University of Pretoria, Pretoria, South Africa. \\ *Correspondence: Sarah Edwards, School of Biological Sciences, Royal Holloway, University of London, Egham \\ Hill, Egham, Surrey, TW20 0EX, UK. Tel. +44 (0)1784 443188. Email: hyenaconflict@gmail.com
}

\begin{abstract}
Discussions regarding the importance of accounting for detection probability have long been present in ecological literature. Various studies have demonstrated the influence of survey design on detection probabilities, and whilst the placement of camera traps along roads is a commonly used survey design, it has shown to be biased towards certain species. In arid environments, water sources have the potential to be efficient sites for camera trap placement. We compared the influence of a water source camera trap survey design on the detection probabilities of a guild of seven carnivore species, in comparison detection probabilities from camera traps along roads, on arid, commercial farmland in southern Namibia. Results showed detection probabilities for all species to be higher at water, with the water source design producing shorter latencies of detections and higher naive occupancy estimates for most species. However, for species with unique markings, the
\end{abstract}


water source design produced lower proportions of images suitable for individual identification. As detection probabilities of all species were influenced in a positive manner, we suggest placing camera traps at water sources in arid environments to be an effective survey design. However, for surveys requiring individual identification, placing camera traps along roads may be more suitable.

\section{Highlights}

- Comparison of two camera trap survey designs for detecting a guild of seven carnivores in Namibia.

- Camera traps placed at permanent water sources compared to traps placed along roads.

- Detection probabilities higher for all species, latency until detection first shorter and naive occupancy estimates higher for most species at water sources.

- Proportions of images suitable for individual identification higher from road camera traps.

- Water source camera trap survey design effective for multiple carnivore species in arid environments, unless individual recognition is required, for which road survey design is more suitable.

Keywords: camera trap, carnivore, detection probability, multiple species, Namibia, survey design 


\section{Introduction}

Within the field of ecology, the issue of imperfect and varying detection probability remains a central theme of discussion (Sollmann et al., 2013), particularly pertaining to the use of relative abundance indices. Whilst statistically sound methods have been developed for those species with unique natural markings (Karanth and Nichols, 1998), relative abundance indices are still frequently used for those species without such markings, which often comprise the majority of species detected during a survey (Carbone et al., 2008). The use of relative abundance comparisons across species, space and time is particularly controversial, as such comparisons rely on the assumption of constant probability of detection (Kellner and Swihart, 2014). However, detection probability has been shown to vary with a number of factors including local density, seasonal or behavioural patterns, amount of area surveyed (Bailey et al., 2004), and survey design (Sollmann et al., 2013), meaning the assumption is unlikely to hold true (O'Connell et al. 2012), but is rarely accounted for (Kellner and Swihart, 2014). This issue has most recently been highlighted by Hayward et al. (2015) as one of the key problems facing the debate regarding the conservation use of dingoes Canis dingo in Australia. Hayward et al. (2015) suggest that conflicting results regarding the species' role in mesopredator suppression may be a merely an artefact of sampling methods used and failure to account for detection probability.

A number of previous studies have highlighted the importance of accounting for detection probability in multi-species surveys, by demonstrating how survey design can be biased towards particular species. Weckel et al. (2006) found both paca Agouti paca and armadillo Dasypus novincinctus had higher detection probabilities away from forest trails in Belize, whilst Harmsen et al. (2010) found off-trail camera traps failed to detect puma Puma 
concolor, ocelots Leopardus pardalis and white-lipped peccary Tayassu pecari, which were detected by trail traps in Belize. Even within a single guild, differential responses to survey design have been shown, for example Bischof et al. (2014) found species-specific differences in site-specific factors influencing detectability when surveying snow leopards Panthera uncia, stone marten Martes foina and red fox Vulpes vulpes. Additionally, in a study of puma and jaguar Panthera onca, two relatively similar species, Harmsen et al. (2010) showed camera traps placed on trails were biased towards puma captures, warning comparisons between relative abundances of the two species are likely to be invalid. In such circumstances, without accounting for the variation in detection probability, it may be difficult to tell if the variation seen between species capture rates is due to differences in abundance or detection probabilities (Foster and Harmsen, 2012).

Survey designs seek to maximise detection probabilities which in turn confers the benefits of higher precision estimates of abundance parameters (White et al., 1982; Karanth and Nichols, 2002; Lukacs and Burnham, 2005), and a decrease in the number of survey days, or sampling periods needed to obtain reliable data (Mackenzie and Royle, 2005; Rovero et al., 2010). However, when there is variation in the influence of the survey design on detection probabilities between species, selecting a single survey design can be problematic. Nevertheless, such an approach is likely to be the most cost effective method of surveying multiple species in a single area. Mann et al. (2014) examined the influence of camera trap placement on the detection probabilities of a range of mammals in the Little Karoo and found detection probabilities in relation to distance from roads to show extensive variation between species, suggesting camera traps placed on roads are effective for surveying carnivores, but not their prey, in an arid environment. 
Many previous carnivore surveys have focused survey efforts on roads and trails, either when using camera traps (e.g. Rios-Uzeda et al., 2007), or sign surveys (e.g. Melville and Bothma, 2006). Such an approach has been suggested to be particularly effective as roads and trails often act as natural funnels through vegetation, directing animal movement through an area (Kelly et al., 2012). Other studies have successfully used baits and lures to increase carnivore detection probabilities (Dillon and Kelly, 2007), for example Thorn et al. (2009) found a fish lure significantly increased encounter rate for brown hyenas Hyaena brunnea, whilst du Preez et al. (2014) found bait to significantly increase capture rate for leopards Panthera pardus. Previous studies have also used camera traps to produce suitable images for individual identification, for example Ngoprasert et al. (2012) used baits to encourage both Asiatic black bears Ursus thibetanus and sun bears Helarctos malayanus to expose the chest area to camera trap to show the chest markings needed for individual recognition, usually not seen when bears walk past camera traps.

The use of baits in surveys is however, debated, with concerns being raised regarding violations of the geographic closure assumption of capture-recapture surveys if the bait causes permanent immigration or emigration onto and off the trapping grid, as well as differences in individual levels of habituation through time (Balme et al., 2014). Gerber et al. (2011) examined the effects of baited camera traps on Malagasy civet Fossa fossana and found baits not to affect immigration or emigration, abundance or density estimates, but did increase precision of these estimates. However, for large African carnivores, the use of baits has also been suggested to raise ethical concerns as it potentially increases individual vulnerability to trophy hunting, which often uses baits (Balme et al. 2014). 
Permanent water sources in an arid environment are rare and attractive to a number of species, therefore it may be considered a natural bait, without the problems associated with more traditional baits introduced into the environment for the duration of a survey only. A recent study by Edwards et al. (2015) showed evidence of temporal, rather than spatial partitioning to be the main mechanism promoting the avoidance of dominant competitors within a carnivore guild at water sources in an arid environment. In contrast, a large body of literature exists suggesting the preferential use of roads by apex predators and the avoidance of them by mesopredators in the presence of apex predators (Hayward and Marlow, 2014). Therefore, in arid environments, water sources have the potential to represent ideal locations for camera trap placement for carnivore surveys, yet the influence of such camera trap placement so far remains untested with regard to its influence on detection probabilities for multiple guild members.

This study examined the influence of camera trap placement on detection probabilities for a guild of eleven carnivore species across two commercial farmlands in southern Namibia, to investigate the potential of this survey design for multiple carnivore species. Detection probabilities produced by camera traps placed at water sources were compared to those produced by cameras placed along roads. Latency until first detection, naive occupancy estimates and species inventories produced by the two camera trap survey designs were also compared. As water is likely to be attractive to numerous carnivore species, and there being no vegetation funnel that may force carnivores to move through the site along roads, it was hypothesised the water source camera trap design would produce higher detection probabilities and naive occupancy estimates as well as shorter latencies until first detection, and a higher diversity of carnivore species inventoried. 
Additionally, as identifying individuals for species with unique natural markings is a fundamental aspect of density estimation, the proportion of photos where individual identification could be made was compared between the two survey designs. Here is was hypothesised the road camera trap survey design would produce higher proportions of photos for individual identification as animals are more likely to pass perpendicularly in front of road camera traps, whereas at water animals may approach from any angle.

\section{Methods}

\subsection{Study site}

The study was conducted across two neighbouring commercial farmlands; Tsirub and Klein Aus Vista (KAV), bordering the Tsau//Khaeb (Sperrgebiet) National Park, Karas region, southern Namibia. A full description of study sites can be found in Edwards et al. (2015).

\subsection{Methodology}

Two camera trap survey designs were compared, one with camera traps located at water sources, and another with camera traps placed along unfenced farm roads. A total of 12 Scoutguard SG560V (HCO Outdoors, Norcross, GA, USA)camera traps were placed at water points (Tsirub $n=7, \operatorname{KAV} n=5$ ), eleven being artificial water troughs and one being a permanent, natural spring on KAV. Scoutguards were programmed to take one photo per trigger, with a minute delay between triggers and set to be active 24 hours per day. A full description of camera traps placed at water sources can be found in Edwards et al. (2015). A total of nine Reconyx HC600 (Reconyx Inc, Holeman, Wisconsin, USA) camera traps (Tsirub $n=5$, KAV $n=4$ ) were placed along farm roads connecting the water sources 
monitored by the water point camera traps, with the mean distance from water source camera traps to the nearest road camera trap being $1.79 \mathrm{~km}$ (range $0.45-4.27 \mathrm{~km}$ ). Reconyx camera traps were programmed to be active 24 hours a day, to take five photos at a time with no delay between triggers and at medium sensitivity. All camera traps within each survey design were spaced 3.5 - $4 \mathrm{~km}$ apart, a distance which was considered to be spatially independent. Camera traps from the road survey design were interspaced between those from the water source survey. In order to try and ensure carnivore populations were demographically closed during the study period, a survey period of 65 days was used, following the recommendations of Karanth and Nichols (1998). Additionally, a dry winter period was used, with no rainfall (29th May - 3rd August 2013), resulting in no changes to surface water availability during the study (S. Edwards, pers. obs.).

\subsection{Data analysis}

Carnivore camera trap images were identified and classed into independent events as described in Edwards et al. (2015). Whilst an occupancy approach may have been more suitable for such a study, the low samples sizes of some carnivore species meant models showed a poor fit to the data, therefore a comparison of relative abundance indices was used. Relative abundance indices for each species were calculated (Edwards et al., 2015), and were viewed as analogous to detection probabilities following Harmsen et al. (2010) and Mann et al. (2014). Mann-Whitney $U$ tests were used to test for significant differences between detection probabilities produced by the water source survey design and the road survey design. Spearman's rank correlation tests were used to test for an association between detection probability and distance from water for road camera traps. Additionally for each species and camera trap survey design, latency until first detection, defined as the 
number of days from initial deployment until a species was first detected (Foresman and Pearson, 1998), was calculated for all positive camera traps, i.e. those which detected the species, along with the naive occupancy; the proportion of camera traps where the species was detected (MacKenzie et al., 2006). Mann-Whitney U tests were also used to test for significant differences in latencies until first detection for the water source survey design and the road survey design. All data analyses were conducted using R 3.1.1 (R Development Core Team, 2014).

For those species having individually unique markings, with sufficient sample sizes, camera trap images were examined to determine if individual identification could be made based on the clarity of markings. The proportion of images where identification could be made was then calculated from the total number of images from each survey design. As road camera traps were set to take five images per trigger with no delay between triggers, and water camera traps set to take one image per trigger, only the first image per trigger was used from road camera traps. Fisher's exact tests were conducted to examine for significant differences in the proportions of images where identification was possible for each survey design.

\section{Results}

Ten carnivore species were recorded over 1,676 trap nights, totalling 1,106 independent events (Table 1). Species detected were Cape fox Vulpes chama $(n=66)$, bat-eared fox Otocyon megalotis $(n=26)$, black-backed jackal Canis mesomelas $(n=894)$, honey badger Mellivora capensis $(n=10)$, aardwolf Proteles cristatus $(n=3)$, spotted hyena $(n=3)$, brown hyena $(n=41)$, leopard $(n=33)$, cheetah Acinonyx jubatus $(n=1)$ and African wild cat Felis lybica $(n=30)$. Due to low sample sizes, aardwolf, spotted hyena and cheetah were 
excluded from analysis. Not every species was detected by both camera trap survey designs; neither Cape fox nor bat-eared fox were detected by camera traps placed at roads.

Table 1: Total numbers of independent events by survey design for carnivore species

\begin{tabular}{lrr}
\hline & $\begin{array}{r}\text { \# of independent events } \\
\text { Wpecies }\end{array}$ & Woter \\
\hline Cape fox & 66 & 0 \\
Bat-eared fox & 26 & 0 \\
Black-backed jackal & 867 & 27 \\
Honey badger & 8 & 2 \\
Aardwolf & 1 & 2 \\
Spotted hyena & 3 & 0 \\
Brown hyena & 33 & 8 \\
Leopard & 23 & 10 \\
Cheetah & 1 & 0 \\
African wild cat & 27 & 3 \\
\hline
\end{tabular}

\subsection{Detection probabilities}

Mean detection probabilities were highest from the water source survey design for all species (Table 2), with Mann-Whitney $U$ tests showing detection probability to be

Table 2. Mean detection probabilities for carnivore species from water and road camera trap survey designs, species with significant differences between detection probabilities produced by the two survey designs highlighted in bold.

\begin{tabular}{|c|c|c|}
\hline \multirow[t]{2}{*}{ Species } & \multicolumn{2}{|c|}{$\begin{array}{l}\text { Mean detection probability (mean number of independent events/100 trap nights) } \\
\text { (S.E) }\end{array}$} \\
\hline & Water & Roads \\
\hline Cape fox & $6.02(5.68)$ & 0 \\
\hline Bat-eared fox & $4.90(0.3)$ & 0 \\
\hline Black-backed jackal & $123.13(33.74)$ & $3.87(2.52)$ \\
\hline Honey badger & $2(0.70)$ & $0.27(0.27)$ \\
\hline Brown hyena & $5.73(1.54)$ & $1.49(0.58)$ \\
\hline Leopard & $3.01(1.05)$ & $1.63(0.77)$ \\
\hline African wild cat & $3.77(2.37)$ & $0.48(0.37)$ \\
\hline
\end{tabular}


rank correlation tests showed no association between detection probability and distance of significantly higher from the water source survey design for black-backed jackal ( $W=100, P$ $=<0.001)$, honey badger $(W=74, P=0.03)$ and brown hyena $(W=77, P=0.03)$. Spearman's road camera traps from water for any species.

\subsection{Latency until first detection}

Mean latency until first detection was significantly shorter for the water source camera trap survey design for black-backed jackal ( $W=0, P=0.006)$ only. Mann-Whitney $U$ tests could not be performed for honey badger and African wild cat, as for both species only one road camera trap detected the species. All other species had shorter latencies at water in comparison to roads (Fig. 1), although not significantly so, with the exceptions of honey badger and leopard, although significant differences were not seen for these species.

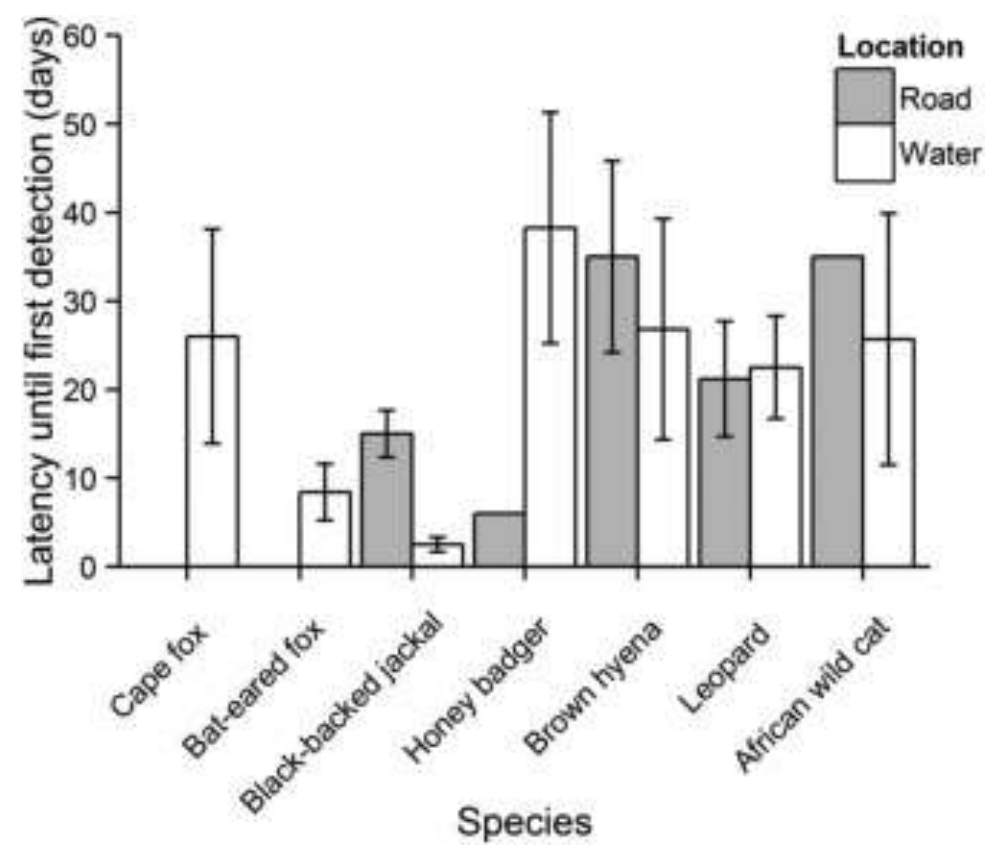

Fig. 1. Mean latency until first detection (days) ( \pm S.E.) for carnivores detected by camera traps, for both road and water source camera trap survey designs. 


\subsection{Naive occupancy}

Naive occupancy estimates were higher for the water source survey design for all species, with the exception of African wild cat, where a difference of just 0.02 was seen (Fig. 2). The biggest difference between naive occupancy estimates for the two survey designs was seen for black-backed jackal, where naive occupancy from the water source survey design was 1.0, whilst naive occupancy from the road survey design was 0.4 .

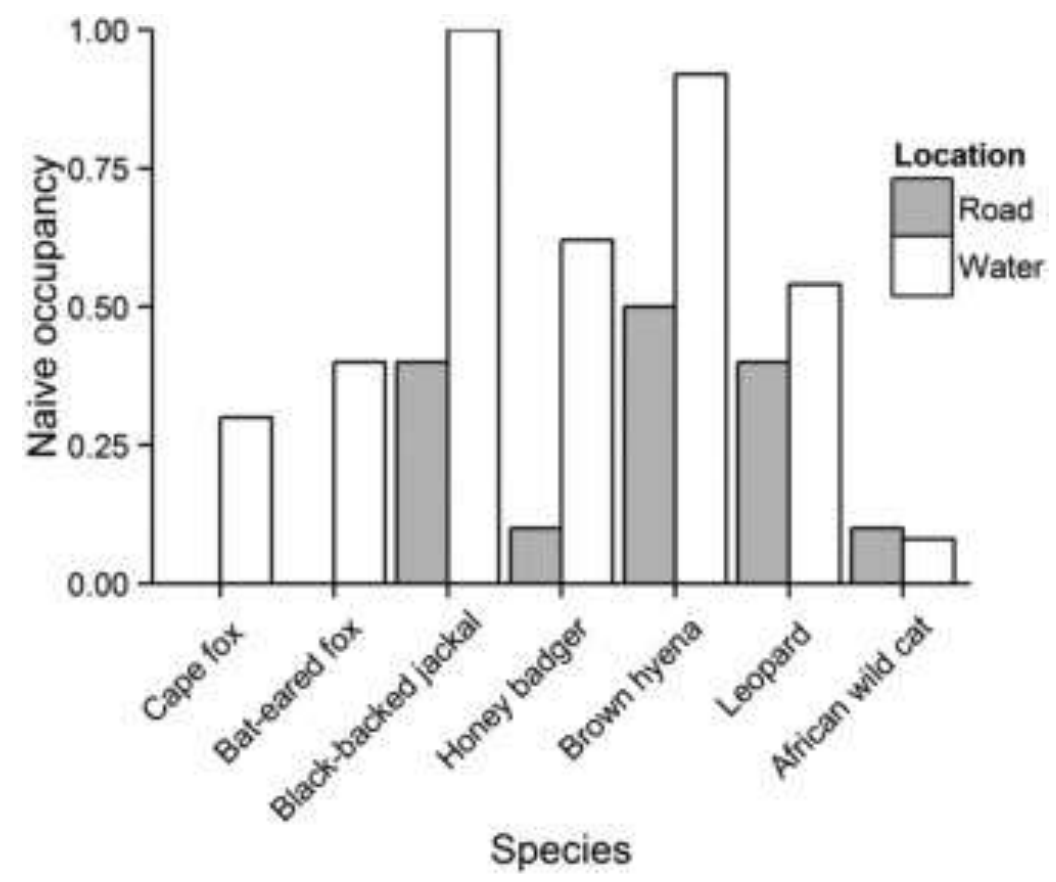

Fig. 2. Naive occupancy estimates (proportion of camera traps to detect species) for both water source and road survey designs.

\subsection{Individual identification}

The three species having sufficient sample sizes and unique natural markings allowing individual identification, brown hyena, leopard and African wild cat, all showed the proportions of photographs suitable from individual identification, i.e. where the strip or rosette pattern was clearly visible, was higher from road camera traps than those placed at water sources. A proportion of $0.6(n=6)$ photos from road camera traps were suitable for identification, compared to $0.13(n=3)$ photos from water source camera traps for brown 
hyena, which was not significantly different (Fisher's exact test, $P=0.07$ ). Leopard showed no significant differences in the proportions of suitable photos between the two survey designs (Fisher's exact, $P=0.41$ ), all photos from road camera traps were suitable for individual identification, compared to 0.61 obtained from water source camera traps. A proportion of 0.67 African wild cat images from road camera traps were suitable for individual identification compared to 0.15 from water source camera traps, which was not significantly different (Fisher's exact test, $P=0.19$ ).

\section{Discussion}

Camera traps have long been acknowledged as being an effective and efficient method of surveying elusive and nocturnal carnivores (Karanth, 1995), with more recent studies examining the effect of camera trap placement on data collected (e.g. Mann et al., 2014). The results of this study highlight the effect of fine-scale camera trap placement on detection probability for a guild of seven sympatric carnivore species in an arid environment. That detection probabilities for all species were higher from camera traps placed at water, and for some species significantly so, in comparison to those produced by camera traps placed along roads, would suggest such a design to be suitable for multiple carnivore species in an arid environment. This finding is also supported by the shorter latency until detection for all species, with the exception of honey badger and leopard, and higher naive occupancy estimates for all species except African wild cat at water sources. Additionally, neither Cape fox nor bat-eared fox were detected by any camera traps from the road survey design, suggesting road camera trap placement may not be suitable for such species. However, as proportions of images suitable for individual identification for species with unique natural markings were higher from the road survey design, although it should 
be noted this was not significantly so, it would suggest road camera placement to be more suitable where identification of individuals is required.

Higher mean detection probabilities, lower latencies until first detection and higher naive occupancy estimates were seen for the water point survey design for most species, suggesting this to be a more effective and efficient method for surveying carnivores in arid environments than cameras placed along roads. High detection probabilities are desirable as they give rise to more precise estimates of abundance (Karanth and Nichols, 2002), whilst shorter latencies until first detection decrease the time needed to record species present in an area. Previous studies have found probability of detection to differ between camera traps placed on and off road, for example both leopard cat Leopardus bengalensis and common palm civet Paradoxurus hermaphroditus in Borneo (Sollmann et al., 2013) were found to have higher detection probabilities on-road in comparison to off-road. That carnivores may have higher detection probabilities on roads in environments where vegetation may restrict movement, is expected, as in such environments roads have been suggested to act as natural funnels through an area (Kelly et al., 2012). Heilburn et al. (2006) believed their high photographic success rate of bobcats Lynx rufus in comparison to previous studies, was due to dense vegetation funnelling bobcats onto roads where camera traps were placed, and hypothesised such a survey design would be not be as successful in habitats with low vegetation density.

In the study site, vegetation density was low, with Stipogrostis grass species dominating much of the area (S. Edwards, pers. obs.), therefore such vegetation was not expected to hinder animal movement, therefore no vegetation funnel existed along roads. Such a factor may explain why this survey design was not as efficient as the water source 
survey design. In contrast Mann et al. (2014) found carnivore detection probability to be higher on roads than directly adjacent to roads in the arid Little Karoo. However, Mann et al. (2014) compared on and off road trap placement, whilst this study compares road and water source placements. In arid environments water is a rare resource, and even on farmlands where water is provided through artificial means, occurs at low density (5.44 troughs $/ 100 \mathrm{~km}^{2}$ for the study area). As a result, water is expected to be an attractant for a large number of species in the area thus explaining the water camera trap survey design was more successful in this arid environment.

The probability of detecting an animal is thought to correlate with body size, with larger bodied species being associated with higher detection probabilities (Tobler et al., 2008; Rowcliffe et al., 2013). Therefore it might not be surprising that the two smallest species as determined by shoulder heights, Cape fox and bat-eared fox, were the only species not detected by road camera traps. Similarly, Srbek-Araujo and Chiarello (2005) found camera traps placed along trails to under-represent small mammal $(<1 \mathrm{~kg})$ diversity in neotropical Brazilian forests. As camera traps were positioned approximately $40 \mathrm{~cm}$ from ground level, they should have been well able to detect bat-eared fox and Cape fox with mean shoulder heights of $30 \mathrm{~cm}$ and $31.5 \mathrm{~cm}$ respectively (Walker, 1996). However, these species were both detected by water source camera traps, suggesting small body size was not the reason for non-detection. Carnivores at water sources tended to stop and drink in front of camera traps, whereas carnivores along roads walked past camera traps, therefore a combination of small body size and fast walking speed past the camera traps may explain why Cape fox and bat-eared fox were missed by road camera traps. Alternatively, the avoidance of roads by mesocarnivores in the presence of apex predators is a well documented phenomenon (Hayward and Marlow, 2014) and might explain the results seen, 
as well as offering as an explanation as to why all mesocarnivore detection probabilities were lower for roads than water. However, road kills of species such as brown hyena (Wiesel, 2010), Cape fox, bat-eared fox, black-backed jackal and African wild cat (Bullock et all, 2011) are relatively common, suggesting these species do commonly make use of roads even when apex carnivores are present. This information again may suggest a combination of small body size and walking speed as an explanation as to such species are not detected along roads.

Differences in detection probability have previously been seen between camera trap brands and models (Kelly \& Holub 2008), and in this study two different brands were used for the two survey designs; Reconyx were used on roads, whilst Scoutguards were used at water points. Cove and Jackson (2011) found differences in detection probability for bobcats between Reconyx and Moultrie camera traps in Missouri, with Reconyx detection probability being twice as high as Moultrie ( 0.23 and 0.11 respectively). Such a difference was suggested to result from the Moultrie's white flash scaring off bobcats before a photo was triggered, compared to the infra-red flash from the Reconyx. Wegge et al. (2004) also found tigers Panthera tigris to become trap-shy over time, believing individuals became scared of the white flash and learnt to avoid camera traps. In this study both brands of camera trap used infra-red, however differences in advertised trigger speeds, the amount of time passing between the camera trap detecting a passing target and capturing an image (Rovero et al., 2013), exist. The Reconyx HC 600 advertises a trigger speed of 0.20 seconds, whilst the Scoutguard 560V specifies a trigger time of 1.2 seconds. Such a difference in trigger speed could be expected to result in lower detection probabilities for camera traps placed at water, however the opposite result was seen. This may imply the trigger speed is 
less important at sites where animals are stationary in front of a camera trap, in comparison to those sites where animals are walking past camera traps.

In addition to the lower detection probabilities seen for all carnivore species in this study, camera traps placed along roads may be associated with problems such as sex biases. Balme et al. (2009) found male leopards to use man-made roads more frequently than females, whilst Salom-Perez et al. (2007) found sex differences in road use for jaguar, with females avoiding man-made trails. Such biases could have important consequences when estimating trophy hunting quotas, which are often calculated as taking a specific percentage of the male population, and should therefore be based on sound information (Spong et al., 2000). Leopard was the only species captured where male and female can easily be identified from photographs, however small sample sizes (see Edwards et al. in press) meant differences in detection probabilities between the sexes could not be analysed statistically. Therefore it would be of interest to examine sex biases in artificial water source use by carnivores in arid environments, to ensure water source camera trap survey designs do not produce sex biases similar to those seen for other species on roads.

Carnivore species are expected to differ in their dependence on water, which may in turn affect response to survey design, however information regarding the water requirements of African carnivores is scant. Sliwa (1996) suggested aardwolves to be generally independent of surface water, being able to obtain sufficient moisture from their diet of termites. This species was rarely detected on either road or water camera traps across the study site, and was therefore believed to occur at low density. Brown hyena are also believed to be independent of fresh drinking water (Wiesel 2015), although this species regularly visited water troughs throughout the study area, suggesting the species will make use of such resources when available. Therefore, as species known to be independent of 
fresh drinking water were either captured too infrequently to include in analysis, or frequented water sources anyway, reaching conclusions regarding the effect of survey design on species independent of water is difficult and is a potential area of future research. Examination of camera trap images suitable for individual identification showed for all three species where individual identification was possible, brown hyena, leopard and African wild cat, road camera traps produced higher proportions of suitable photos. Garrote et al. (2012) found baited camera traps produced a higher proportion of images suitable for identification than unbaited traps for Iberian lynx Lynx pardinus, suggesting this is a result of lynx spending more time in front of camera traps with bait. Similarly, du Preez et al. (2014) suggested leopards to spend more time in front of baited traps whilst eating thus increasing the number of images captured which improve the accuracy of identification through multiple views of the same individual. Additionally, Garrote et al. (2014) hypothesised baits caused animals to spend more time in front of traps to overcome problems with slow trigger speeds.

Whilst carnivores are likely to spend more time in front of camera traps placed at water as they stop to drink, in comparison to road camera traps, often the angle of approach to the water trough may mean the camera triggers whilst the animal is still far from the trap, or a face on shot is obtained, not suitable for identification. In comparison, road camera traps are positioned perpendicularly to roads meaning carnivores pass in front of camera traps, and are usually captured so that the whole flank of the animal is in view and when used in pairs with each trap on one side of a road, images of both the left and right hand side of the animal can be obtained. Therefore, for species where individual identification is needed for density estimation, camera traps placed along roads may 
provide a better survey design than traps placed at water sources. However, it is also worth trialling the use of the 'burst' setting many camera traps offer, i.e. where multiple photos are taken from a single trigger, or having no delay between triggers, which may result in more suitable photos for individual identification.

In arid environments, where carnivores often occur at low densities (Hayward et al., 2007), low sample sizes are often expected, and therefore any survey design which increases probability of detection, is likely to aid researchers. The results of this study would suggest placing camera traps at water points in arid environments when surveying a guild of sympatric carnivores to be extremely effective. Such an approach was only possible here given that there were a number of water points distributed throughout the study area, for sites where water points occur at a lower density with larger distances between them, this approach would not be possible, and further research would be warranted on camera trap survey designs in such environments. Particularly encouraging has been the fact that this survey design influenced the detection probabilities of all carnivore guild members in a positive manner and therefore was not considered to be biased towards or against any particular species. However, it is of importance that the proportions of images suitable for individual identification were lower from the water source camera trap survey design. For studies requiring identification of individuals, such as density estimations, it is therefore recommended the road survey design is used to ensure a sufficient numbers of identifiable images are obtained. 


\section{Acknowledgements}

We are grateful for financial support from the Nedbank Go Green Fund Namibia, Namdeb Diamond Corporation and Royal Holloway, University of London. Research permits were provided by the Ministry of Environment and Tourism, Namibia for which we are grateful. Permission to work on the study sites was granted by the Swiegers family and Mr K Bosman to whom we are indebted to. Thanks to all research assistants working on the project.

\section{References}

1. Bailey, L. L., Simons, T. R. \& Pollock, K. H. (2004). Estimating site occupancy and species detection probability parameters for terrestrial salamanders. Ecological Applications 14, 692-702.

2. Balme, G., Hunter, L. \& Robinson, H. (2014). Baited camera-trap surveys - marginally more precise but at what cost? A response to du Preez et al. (2014). Biological Conservation 179, 144-145.

3. Balme, G. A., Hunter, L. T. B. \& Slotow, R. (2009). Evaluating methods for counting cryptic carnivores. Journal of Wildlife Management 73, 433-441.

4. Bischof, R., Hameed, S., Ali, H., Kabir, M., Younas, M., Shah, K. A., Din, J.U. \& Nawaz, M. A. (2014). Using time-to-event analysis to complement hierarchical methods when assessing determinants of photographic detectability during camera trapping. Methods in Ecology and Evolution 5, 44-53.

5. Bullock, K. L., Malan, G. \& Pretorius, M. D. (2011). Mammal and bird road mortalities on the Upington to Twee Rivieren main road in the Southern Kalahari, South Africa. African Zoology, 46, 60-71.

6. Carbone, C., Christie, S., Conforti, K., Coulson, T., Franklin, N., Ginsberg, J. R., Griffiths, M., Holden, J., Kawanshi, K., Kinnaird, M., Laidlow, R., Lynam, A., MacDonald, D.W., Martyr, D., McDougal, C., Nath, L., O'Brien, T., Seidensticker, J., Smith, D.J.L., Sunquist, M., Tilson, R. \& Wan Shahruddin, W. (2008). The use of photographic rates to estimate densities of tigers and other cryptic mammals. Animal Research 4, 75-79. 
7. Cove, M. V. \& Jackson, V. L. (2011). Differences in detection probability between camera trap types for surveying bobcats in a fragmented suburban landscape. Wild Felid Monitor 4, 24.

8. Dillon, A. \& Kelly, M. J. (2007). Ocelot Leopardus pardalis in Belize: the impact of trap spacing and distance moved on density estimates. Oryx 41, 469-477.

9. du Preez, B. D., Loveridge, A. J. \& Macdonald, D. W. (2014). To bait or not to bait: a comparison of camera-trapping methods for estimating leopard Panthera pardus density. Biological Conservation 176, 153-161.

10. Edwards, S., Aschenborn, A., Gange, A.C. \& Wiesel, I. (in press). Leopard density estimates from semidesert commercial farmlands, southwest Namibia. African Journal of Ecology, in press

11. Edwards, S., Gange, A. C. \& Wiesel, I. (2015). Spatiotemporal resource partitioning of water sources by African carnivores on Namibian commercial farmlands. Journal of Zoology n/a-n/a. doi:10.1111/jzo.12248.

12. Foster, R. J. \& Harmsen, B. J. (2012). A critique of density estimation from camera-trap data. The Journal of Wildlife Management 76, 224-236.

13. Foresman, K. R. \& Pearson, D. E. (1998). Comparison of proposed survey procedures for detection of forest carnivores. The Journal of Wildlife Management 62, 1217-1226.

14. Garrote, G., Gil-Sánchez, J. M., McCain, E. B., Lillo, S., Tellería, J. L. \& Simón, M. Á. (2012). The effect of attractant lures in camera trapping: a case study of population estimates for the Iberian lynx (Lynx pardinus). European Journal of Wildlife Research 58, 881-884.

15. Gerber, B. D., Karpanty, S. M. \& Kelly, M. J. (2011). Evaluating the potential biases in carnivore capture-recapture studies associated with the use of lure and varying density estimation techniques using photographic-sampling data of the Malagasy civet. Population Ecology 54, 43-54.

16. Harmsen, B. J., Foster, R. J., Silver, S., Ostro, L. \& Doncaster, C. P. (2010). Differential use of trails by forest mammals and the implications for camera-trap studies: a case study from Belize. Biotropica 42, 126-133.

17. Hayward, M. W., Boitani, L., Burrows, N. D., Funston, P. J., Karanth, K. U., MacKenzie, D. I., Pollock, K.H. \& Yarnell, R. W. (2015). Ecologists need robust survey designs, sampling and analytical methods. Journal of Applied Ecology n/a-n/a. doi:10.1111/1365-2664.12408. 
18. Hayward, M. W. \& Marlow, N. (2014). Will dingoes really conserve wildlife and can our methods tell? Journal of Applied Ecology 51, 835-838.

19. Hayward, M., O'Brien, J. \& Kerley, G. (2007). Carrying capacity of large African predators: predictions and tests. Biological Conservation, 139, 219-229.

20. Heilbrun, R. D., Silvy, N. J., Peterson, M. J. \& Tewes, M. E. (2006). Estimating bobcat abundance using automatically triggered cameras. Wildlife Society Bulletin 34, 69-73.

21. Karanth, K. U. (1995). Estimating tiger (Panthera tigris) populations from camera-trap data using capture-recapture models. Biological Conservation 71, 333-338.

22. Karanth, K. U. \& Nichols. J.D. (1998). Estimation of tiger densities in India using photographic captures and recaptures. Ecology 79, 2852-2862.

23. Karanth, K.U, \& Nichols, J.D. (2002). Monitoring tigers and their prey: A manual for researchers, managers and conservationists in tropical Asia. Centre for Wildlife Studies, Bangalore, India.

24. Kellner, K. F. \& Swihart, R. K. (2014). Accounting for imperfect detection in ecology: a quantitative review. PLOS ONE 9, e111436.

25. Kelly, M.J., Betsch, J., Wultsch, C., Mesa, B. \& Mills, L.S. (2012). Non-invasive sampling for carnivores. In Boitani, L. \& Powell, R.A. (Eds). Carnivore ecology and conservation. Oxford University Press, Oxford, United Kingdom.

26. Kelly, M. J. \& Holub, E. L. (2008). Camera trapping of carnivores: trap success among camera types and across species, and habitat selection by species, on Salt Pond Mountain, Giles County, Virginia. Northeastern Naturalist 15, 249-262.

27. Lukacs, P.M. \& Burnham, K.P. (2005). A review of capture-recapture methods applicable to noninvasive genetic sampling. Molecular Ecology 14, 3909-3919.

28. MacKenzie, D.I., Nichols, J.D., Royle, J.A., Pollock, K., Bailey, L. \& Hines, J.E. (2006). Occupancy estimation and modelling. Inferring patterns and dynamics of species occurrence. Elsevier Publishing, London, UK.

29. Mackenzie, D. I. \& Royle, J. A. (2005). Designing occupancy studies: general advice and allocating survey effort. Journal of Applied Ecology 42, 1105-1114. 
30. Mann, G. K. H., O’Riain, M. J. \& Parker, D. M. (2014). The road less travelled: assessing variation in mammal detection probabilities with camera traps in a semi-arid biodiversity hotspot. Biodiversity and Conservation 24, 531-545.

31. Melville, H. I. A. S., \& Bothma, J. Du. P. (2006). Using spoor counts to analyse the effect of small stock farming in Namibia on caracal density in the neighbouring Kgalagadi Transfrontier Park. Journal of Arid Environments 64, 436-447.

32. Ngoprasert, D., Reed, D., Steinmetz, R. \& Gale, G. (2012). Density estimation of Asian bears using photographic capture-recapture sampling based on chest marks. Ursus 23, 117-133.

33. O’Connell, A. F. O., Talancy, N. W., Bailey, L. L., Sauer, J. R., Gilbert, A. T. \& Carolina, N. (2012). Estimating site occupancy and detection probability parameters for meso- and large mammals in a costal ecosystem. Journal of Wildlife Management 70, 1625-1633.

34. R Development Core Team (2014). R: A language and environment for statistical computing. Version 3.1.1. R Foundation for Statistical Computing, Vienna, Austria.

35. Rios-Uzeda, B., Gomez, H. \& Wallace, R. B. (2007). A preliminary density estimate for Andean bear using camera-trapping methods. Ursus 18, 124-128.

36. Rovero, F., Tobler, M., Sanderson, J. (2010). Camera trapping for inventorying terrestrial vertebrates. In Eymann, J., Degreef, J., Haüser, C., Monje, J.C., Samyn, Y. \& VanSpiegel, D. (Eds.). Manual on field recording techniques and protocols of all taxa biodiversity inventories and monitoring. Abc Taxa, Vol. 100-128.

37. Rovero, F., Zimmermann, F., Berzi, D. \& Meek, P. (2013). Which camera trap type and how many do I need? A review of camera features and study designs for a range of wildlife research applications. Hystrix 24, 148-156.

38. Salom-Pérez, R., Carrillo, E., Sáenz, J. C. \& Mora, J. M. (2007). Critical condition of the jaguar Panthera onca population in Corcovado National Park, Costa Rica. Oryx 41, 51-56.

39. Sliwa, A. (1996). A functional analysis of scent marking and mating behaviour in the aardwolf, Proteles cristatus (Sparrman, 1783). PhD Thesis, University of Pretoria.

40. Sollmann, R., Mohamed, A., Samejima, H. \& Wilting, A. (2013). Risky business or simple solution relative abundance indices from camera-trapping. Biological Conservation 159, 405-412. 
41. Spong, G., Hellborg, L. \& Creel, S. (2000). Sex ratio of leopards taken in trophy hunting: genetic data from Tanzania. Conservation Genetics, 1, 169-171.

42. Srbek-Araujo, A. C. \& Chiarello, A. G. (2005). Is camera-trapping an efficient method for surveying mammals in Neotropical forests? A case study in south-eastern Brazil. Journal of Tropical Ecology 21, $121-125$.

43. Thorn, M., Scott D.M., Green, M., Bateman, P.W. \& Cameron, E.Z. (2009). Estimating brown hyaena occupancy using baited camera traps. South African Journal of Wildlife Research 39, 1-10.

44. Walker, C. (1996). Signs of the Wild. Struik Publishers, Cape Town, South Africa.

45. Weckel, M., Giuliano, W. \& Silver, S. (2006). Jaguar (Panthera onca) feeding ecology: distribution of predator and prey through time and space. Journal of Zoology 270, 25-30.

46. Wegge, P., Pokheral, C. P. \& Jnawali, S. R. (2004). Effects of trapping effort and trap shyness on estimates of tiger abundance from camera trap studies. Animal Conservation 7, 251-256.

47. Wiesel, I. 2015. Parahyaena brunnea. The IUCN Red List of Threatened Species. Version 2015.2. <www.iucnredlist.org>. Downloaded on 17 July 2015.

48. Wiesel, I. (2010). Specialist Report: Effects of proposed mining operations in the Southern Resource Area on brown hyenas. Brown Hyena Research Project, Lüderitz, Namibia.

49. White, G.C., Anderson, D.R., Burnham, K.C. \& Otis, D.L. (1982). Capture-recapture and removal methods for sampling closed populations. Los Alamos National Laboratory, New Mexico, United States. 